\title{
A PROPÓSITO DE CLASE, RAZA Y GÉNERO ¿Explotación, exclusión o discriminación?1
}

\section{Yolanda Hernández Cortés ${ }^{2}$}

Las reformas y los cambios legales, aunque mejoren las condiciones de las mujeres y sean parte fundamental de su proceso de emancipación, no van a cambiar de raíz el patriarcado. Hay que integrar estas reformas dentro de una vasta revolución cultural con el fin de transformar el patriarcado y abolirlo.

Gerda Lerner ${ }^{3}$

\section{Resumen}

La tesis que pretendemos sostener en este ensayo hace referencia a las interceptaciones que se presentan entre las categorías clase, raza y género y las categorías explotación, exclusión y discriminación dentro de las discusiones contemporáneas.

\section{Palabras claves}

Género - discriminación, clase - explotación, raza- exclusión.

\section{Abstract}

We assume to hold in this essay a thesis related to the obstacles presented among the categories classes, race and gender with the exploitation, exclusion and discrimination categories in the contemporary discussions.

\section{Index terms}

Gender-discrimination, class-exploitation, race-exclusion.

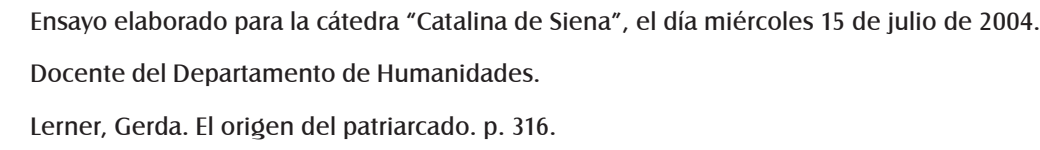


Cuando me disponía a redactar este ensayo, dos días después de la celebración de la Virgen de Chiquinquirá, "El Espectador" de Bogotá informó que en El Pozón, el barrio de la vida en Cartagena, se puede encontrar la historia de más de 300 mujeres desplazadas que se unieron con el fin de vencer esta "realidad" a la cual se han visto forzadas. El semanario también señalaba que casi todas son negras y viudas. Todas ellas, mediadas por "un discurso femenino de empoderamiento", exigen que se las indemnice y que se les repare el daño padecido 4 .

Por fortuna no se trata de un episodio aislado, sino de un hecho que se comienza a visibilizar desde distintas experiencias dentro del país ${ }^{5}$. Ante estos hechos noticiosos se hace necesario adentrarnos en los estudios de género para darle un trasfondo teórico a estas experiencias humanas. Desde esta perspectiva presentaremos a continuación el debate entre Nancy Fraser y Judith Butler acerca de las relaciones entre los problemas de distribución económica y reconocimiento de la identidad de género.

Leyendo la respuesta de Fraser ${ }^{6}$ a las críticas de Butler ${ }^{7}$, vuelven a emerger en mí las incorformidades que experimenté frente a "lusticia interrupta" ${ }^{8}$. Como se sabe, en dicha obra se cuestiona el desplazamiento ocurrido en la teoría social y política actual, que abandonó el enfoque económico basado en las diferencias de clase a favor de la perspectiva culturalista centrada en la diversidad étnica. Sin embargo, frente a la recuperación neomarxista del análisis de clase, cabe interrogar a Fraser hasta qué punto puede hablarse de la explotación económica sin relacionarla con la exclusión cultural y con la discriminación de género. No olvidemos que el ros- tro de la pobreza, por lo general, es el de una mujer negra o indígena.

A continuación abordaremos el problema en tres etapas. La primera está destinada a cuestionar la lectura de Fraser sobre reconocimiento y redistribución. La segunda muestra los límites de la posición de Butler al reducir el problema de la identidad a la identidad sexual. Por último, se contrastan las dos doctrinas y se esboza la posibilidad de enfoques más amplios que respondan integralmente a los problemas de explotación, exclusión y discriminación.

\section{1. ¿Reconocimiento 0 redistribución?}

Para trabajar este aspecto, me centraré en el capítulo de lustitia Interrupta titulado "iDe la redistribución al reconocimiento?: Dilemas en torno a la justicia en una época "potsocialista". Allí, Fraser plantea de forma tajante el problema:

"En estos conflictos postsocialistas, la identidad de grupo sustituye a los intereses de clase como mecanismo principal de movilización política. La dominación cultural reemplaza a la explotación como injusticia fundamental. Y el reconocimiento cultural desplaza a la redistribución socioeconómica como remedio a la injusticia y objetivo de la lucha política" ${ }^{9}$.

Ante el derrumbe del socialismo real a comienzos de los noventa, al parecer han fracasado tanto el diagnóstico como el tratamiento marxista de la enfermedad social, y son sustituidos por nuevos métodos de análisis y corrección. El problema fundamental ya no se percibe

4 Cf. El Espectador, Bogotá, domingo 11 de julio de 2004, p. 2 A.

5 Por mencionar sólo otra nota periodística, en mayo de 2004, en el mismo diario, se presenta el diálogo entre Beatriz Aguirre y Ana Falú hablando de las necesidades de las mujeres indígenas desplazadas y sus diferencias culturales y raciales con las mujeres de la ciudad.

$6 \quad$ Fraser, Nancy. Heterosexismo, falta de reconocimiento y capitalismo: una respuesta a Judith Butler, pp. 124-136.

$7 \quad$ Butler, Judith. El marxismo y lo meramente cultural, pp. 109-123.

8 Fraser, Nancy. ¿De la redistribución al reconocimiento?: Dilemas en torno a la justicia en una época postsocialista, pp. 17-54.

$9 \quad$ Ibíd., p. 17 
en la explotación económica que padecen las clases trabajadoras y campesinas a manos de las clases privilegiadas terratenientes y burguesas. En consecuencia, el motor de la historia no reside más en la lucha de clases que en defensa de sus intereses negados emprendan el proletariado y los demás sectores que padecen el despojo económico. Ni la búsqueda de la justicia socioeconómica sirve de fórmula que remedie las patologías originadas en la desigual distribución de los bienes materiales. En lugar de redistribuir, la nueva interpretación ve en el reconocimiento cultural de las minorías étnicas la clave para solucionar los conflictos sociales. La exclusión cultural se considera ahora como el problema fundamental que deben resolver las políticas públicas. Y la movilización social pasa fundamentalmente por las identidades construidas por los agentes dentro de sus grupos de vida.

Por medio de algunas preguntas, analicemos con mayor detenimiento la descripción de Fraser sobre la situación actual de los estudios sociales.

\section{¿Qué quiere decir que la identidad de grupo sustituye a los intereses de clase?}

Este planteamiento daría la impresión de que quienes han reivindicado intereses de clase no fueran grupos conformados alrededor de unos elementos que les permiten identificarse como tales. Es curioso que Fraser, quien parte de cuestionar esta división entre identidad de grupo e interés de clase, al cabo la admite, en tanto insiste en contraponer la redistribución al reconocimiento.

\section{¿Qué quiere decir que la dominación cultural reemplaza a la explotación?}

Este planteamiento daría la impresión de que quienes han venido explotando, es decir, los explotadores, no pertenecieran a una cultura que domina a otras culturas, es decir, las culturas explotadas. De nuevo Fraser, quien denuncia el reduccionismo culturalista, cae en las redes de éste al ofrecer la alternativa de una clase desculturalizada.

\section{¿Qué quiere decir que el reconocimiento cultural desplaza a la redistribución socloeconómica?}

Según este planteamiento, daría la impresión de que la redistribución socioeconómica tiene que ver con volver a distribuir los "bienes económicos" que se han concentrado (en la medida en que se los han apropiado a aquello, por supuesto despojando a otros de ellos) en las manos de unos pocos. Pero no le pone rostro ni a quienes se han apropiado ni de lo que se han apropiado. Considero que la apropiación no sólo ha sido de capital económico sino de capital simbólico y cultural, razón por la cual el reconocimiento no puede darse sin la redistribución de todos estos bienes en su conjunto. Por lo cual el reconocimiento no se puede dar sin la redistribución. Una vez más, Fraser cae en los vacíos que descubre en las culturalistas.

En síntesis, el problema con Fraser estriba en que la distinción analítica entre redistribución y reconocimiento no le permite percatarse de que los problemas de injusticia tienen rostro y ese rostro por lo general corresponde al de las mujeres (problema de identidad), no blancas (problema étnico) y por su puesto despojadas de capital (problema de clase - dentro del cual se juega el capital simbólico y el capital cultural).

Para Fraser, en cambio, "... los dos tipos de solución van en direcciones opuestas y no es fácil perseguirlos de modo simultáneo. Mientras la lógica de la redistribución implica eliminar las diferencias como tales, la lógica del reconocimiento implica valorizar la especificidad"10 . La primera parte de este planteamiento daría la impresión de estar soportado por uno de los valores del liberalismo, el igualitarismo. Frente a ello, me pregunto si somos iguales, iqué estamos reivindicando? Porque no estamos en posiciones iguales es que se hace una demanda de justicia. Es bueno preguntarse en este punto cómo alguien puede ser sin estar inscrito dentro de un orden cultural y sin la pertenencia a un grupo en particular.

$10 \quad$ Ibíd., p. 34 
¿Y qué quiere decir que la lógica del reconocimiento implica valorizar la especificidad? Este planteamiento parecería estar soportado por uno de los valores más caros a la cultura moderna, el de la autenticidad. Autenticidad que no logran expresar las categorías de las ciencias sociales. Las categorías analíticas son elaboraciones que hacemos para movernos en el mundo pero no son el mundo, el mundo tiene una serie de matices que no alcanzan a ser expresados en las generalidades de las categorías. Por lo tanto, la especificidad siempre ha estado allí y tal vez el problema ha sido justamente ese, el que hemos tratado de aplicar un mismo modelo para captar realidades tan diversas, razón por la cual no podemos dar cuenta del empobrecimiento no sólo económico sino cultural.

En definitiva, cuando Nancy Fraser plantea la idea de una lógica para mirar la redistribución y otra lógica para mirar el reconocimiento, plantea una dicotomía que no es tal. Para mí, este es el problema. Pues los dos tipos de solución no van en direcciones opuestas y sí deben perseguirse de modo simultaneo (esto parafraseando a la misma autora.)

\section{A propósito de "Identidades"}

"iEs posible distinguir, aún analíticamente, entre la falta de reconocimiento cultural y la opresión material cuando la misma definición de persona legal está rigurosamente constreñida por las normas culturales que son indisociables de sus efectos materiales?"11.

Judith Butler es una escritora que se caracteriza por sus planteamientos de tipo deconstructivista. Sin embargo, cuando plantea que la opresión material no es disociable de la falta de reconocimiento, tiene en mente las reivindicaciones del mundo gay/lesbiano-queer y otros. Es decir, parece que en Butler la cuestión del reconocimiento se reduce al reconocimiento del mundo que, a partir de lo que se ha dado en llamar “identidades sexua- les", han venido construyendo una serie de sujetos. Sobra decir que no tengo nada en contra de este tipo de grupos y de movimientos, pero sospecho que la discusión a propósito del reconocimiento y la redistribución no puede quedar circunscrita a la discusión sobre la identidad sexual meramente, pues podríamos hablar de una gran porción de la humanidad que ha venido sufriendo los impactos que implica su desconocimiento tanto étnico como cultural en sentido amplio.

En este punto quisiera apoyarme en Yuderkys Espinosa para preguntar " $i E n$ efecto qué ha sido la identidad sino el sistema de regulación y control de las subjetividades, de manera que las y los sujetos respondan a los patrones de poder preestablecidos? Cuando digo soy mujer o soy negra, o soy las dos cosas, ia que sistema de representación de mí misma estoy apelando? ¿Qué mecanismos de inteligibilidad estoy poniendo en marcha? ¿Qué significado tiene para quien me escucha el ser negra, el ser mujer? ¿Hay como tal un ser "negro", una esencia negra?..."12.

Las sospechas reflexivas que introduce esta autora con relación al tema de la identidad son importantes y de gran pertinencia, ya que en América Latina no hemos sido ajenos a este tipo de reflexiones dada nuestra condición permanente de sub-culturas, o de culturas no desarrolladas, y más recientemente de culturas en vías de desarrollo. Por lo tanto, el tema del reconocimiento no puede circunscribirse, insisto, al tema de la sexualidad; ni desconocerse su carácter problemático.

Ahora bien, existen dos ideas básicas de esta autora que deseo rescatar porque las considero de gran ayuda para plantearnos el tema del reconocimiento en una perspectiva mucho más amplia a la propuesta por Butler y tematizada por Fraser. Yuderky señala: "No creo que sería posible la existencia de un sujeto que no sabe al menos temporariamente lo que es o lo que no es (o quizás mejor, en lo que está), lo que estoy tratando de

$11 \quad$ Butler. Op. Cit., p. 117

12 Espinosa, Yuderkys. Una propuesta de repensar la identidad y nuestras políticas de identidad en los movimientos feministas y étnico-racial. 8 p. 
afirmar es la necesidad de evaluar la política de identidad como restrictiva, ... cuando se trata de aplicarla a contextos, ...en donde la procedencia, el origen, es tan múltiple, como las fusiones que de él se sacan. ...La complejidad identitaria de los pueblos compuestos (esos que nacieron de la eliminación de otros pueblos) nos coloca, nos ha colocado ante la disyuntiva de apelar a una de las identidades primarias, o a reconsiderar la posibilidad de que ampliar el abanico de posibilidades tiene ya valor en sí mismo y es un acto de liberación" ${ }^{\prime \prime 3}$.

Sin embargo, no podemos ser ingenuos. Nuestras posibilidades de re-construcción están inscritas dentro de espectros mucho más amplios que no dependen, para decirlo en palabras de Bourdieu ${ }^{14}$, de un acto voluntarista sino de la transformación real de las estructuras sociales que finalmente son los espacios simbólicos a la luz de los cuales se constituyen los sujetos.

Los principios de igualdad, libertad y autoderminación que presupone el liberalismo no operan de manera automática e igual para todos los grupos. Y en este punto quisiera ofrecer un ejemplo de otra índole para repensar el tema del reconocimiento/redistribución, “...Los estímulos al cultivo del cacahuete para la exportación tuvieron consecuencias complejas y dañinas para el medio ambiente en el Sahel. .... Níger ocupaba una posición subordinada en la economía mundial. Esto hacia que el país se enfrentase a unas condiciones de intercambio cada vez menos favorables y que redoblase sus desesperados esfuerzos para sobreponerse a la situación, mediante una mayor concentración en el monocultivo comercial del cacahuete. Estas y otras razones provocaron hambrunas y la destrucción del entorno natural. La destrucción ecológica y el hambre no se debieron a los campesinos ni a las sequías. Fueron la consecuencia de que fuerzas estructurales complejas e impersonales, en gran medida externas al Sahel, impusieran prácticas agrícolas y cultivos ajenos a la región" ${ }^{\prime \prime 5}$.

\footnotetext{
Ibíd., p. 4

Cf. Bordieu, Pierre. La dominación masculina. 159 p.

Petras, James. Género, raza, clase y ecología., pp. 64-71.
}

Por lo tanto, cuando planteo que el tema del reconocimiento no puede reducirse al tema de la identidad sexual estoy pensando en los múltiples contextos socio-culturales dentro de los cuales estas identidades se constituyen y que también tienen que ser tematizados no sólo en términos re-distributivos, sino en términos de sus riquezas específicas que estimulan sistemas de re-organización social múltiples, tanto del capital económico como del capital simbólico.

\section{Hacia un enfoque integrado}

Hoy por hoy los teóricos se debaten entre la categoría etnia y la categoría raza. En algunos textos se habla de "Género, raza y clase", en otros no queda muy claro a qué se está haciendo referencia cuando se habla de "género, raza y clase", ya que en muchas ocasiones se usa indistintamente la categoría etnia, cultura e identidad.

¿Cómo hablar, entonces, de un punto de vista, cuando son múltiples los puntos de vista? Tratando de buscar el enfoque que mejor me permita abordar la cuestión del género, la raza y la clase, no me he ido por rutas terminológicas tratando de hacer precisiones semánticas que dependiendo de la postura teórica desde la cual se miren se dirá que son rutas artificiosas, dado que el género, la raza y la clase no existen sino que son construcciones culturales (posiciones culturalistas y deconstrucctivistas). Otros echarán de menos el esfuerzo de aclaración conceptual, dado que debe ser posible hablar en nombre de algo o de alguien, ya sea el género, la raza o la clase (posiciones universalistas/ reformistas).

En un primer momento, mi inconformidad tenía que ver justamente con la observación que le hace Butler a Fraser de privilegiar la redistribución frente al reconocimiento; es decir, el privilegiar la cuestión económica frente a la cuestión cultural. No obstante, mi molestia 
es de índole distinta a la de Butler, dado que esta autora lo que parece no compartir con Fraser es la posición de segundo plano a la que queda reducido todo el tema de la igualdad sexual/homosexualidad.

Por supuesto, comparto gran parte de los cuestionamientos que desde el feminismo se han movilizado contra el patriarcalismo. También comparto aquellas posiciones que han venido planteando que la cuestión de género no se circunscribe a lo meramente sexual y que la cuestión hoy es la de la interrelación entre el género, la clase y la etnia.

Sin embargo, me parece percibir en algunas propuestas que la discusión por lo cultural se plantea en tanto que buscamos que se reconozca la "diversidad sexual", discusión que parecería por momentos estar atravesada por una serie de presupuestos universalistas, como el supuesto del individuo liberal, el supuesto de la autodeterminación y el supuesto de la libertad para... En últimas, se trata de suponer unos valores culturales dominantes de sociedades "liberales" que dan por sentado que sus valores y el modelo de desarrollo que está implicado allí es el modelo de sociedad deseado por todos y que no hay posibilidad siquiera para soñar con otras formas de organización social seguramente más solidarias.

En este punto, me dan ganas de soñar. Sin embargo, me detengo y me pregunto, iserá pertinente, posible, admisible esto en este contexto discursivo en el cual me encuentro? ¿ En este contexto institucionalizado de la escritura como valor social público, de este ejercicio académico? Pero el recordar las palabras de Gayle Rubin me motiva a ello, pues en un momento de su texto plantea "...el movimiento feminista tiene que soñar con algo más que la eliminación de la opresión de las mujeres: tiene que soñar con la opresión de las sexualidades y los roles sexuales obligatorios. El sueño que me parece más atractivo es el de una sociedad andrógina y sin género (aunque no sin sexo), en la que la anatomía sexual no tenga ninguna importancia para lo que es una persona, lo que hace, y con quien hace el amor" ${ }^{16}$.

Cuando la leía, me preguntaba cómo es posible que escriba en estos términos, y la respuesta que me daba era, bueno, pues es feminista, o por lo menos parece que escribe en ese contexto de lo que llamamos los discursos de género, y parece que allí hay permiso para hablar y escribir de esta manera. Bajo esta motivación y justificación me muevo.

Yo, por mi parte, sueño con que los discursos de género que circulan en América Latina y en Colombia no sólo nos introduzcan en el reconocimiento jurídico de las diferencias sexuales, sino que abarquen de modo integral el reconocimiento cultural. El problema para mí implica un aspecto más complejo, y es a ello a lo que quiero referirme a continuación.

Partamos de interrogarnos qué quieren las mujeres de América Latina. Creo que esta es una pregunta tan compleja como preguntarse qué quieren las mujeres, qué quieren las lesbianas, qué quieren los gay, etc., preguntas que como hemos visto han generado un sinnúmero de discusiones teóricas y de posiciones discursivas, así como una serie de políticas, ya sea de reconocimiento o de reparación, que por supuesto dependiendo del contexto se transforman en mejores posibilidades para quienes son beneficiarios de las mismas. Pero por supuesto que hasta aquí lo único que hemos podido constatar no es la posibilidad de un cambio cultural sino la inserción en la cultural patriarcal dominante y estructural de aquellos que se han atrevido a cuestionarla: mujeres, lesbianas, gay.

¿Pero qué hay de otras posibilidades culturales? No meramente del mundo soñado por Rubin ${ }^{17}$, donde el sexo no importe y donde cada quien pueda hacer el amor con quien quiera y donde quiera; donde los sadomasoquistas puedan ir al trabajo con sus fetiches para que así no tengan que jugar a la doble moral de ser lo que no son a la luz pública; es más, donde parecería

16 Rubin, Gayle. El tráfico de mujeres: notas sobre la economía política del sexo., pp. 15-74.

$17 \quad$ Cf. Rubin, Gayle. Reflexionando sobre el sexo: notas para una teoría radical de la sexualidad., pp. 113-190. 
desaparecer la diferencia entre lo privado y lo público, porque lo privado es públicamente reconocido, y por lo tanto plantear esta distinción resulta innecesario. Sin embargo, no sé por qué este mundo de ensueño de Rubin y de otras autoras no me emociona; por el contrario, me asusta.

Me asusta el no tener un mundo privado precisamente para poder soñar, para soñar sin pretender que mis sueños se traduzcan en normas para otros, dado que a veces mis sueños me aprisionan y quisiera huir de ellos sabiendo que tengo la posibilidad de volver a ellos sin más porque son sueños y puedo ir y venir de ellos sin pretender constituirlos en estructuras, pues me complace más su carácter etéreo. Definitivamente creo que no comparto aquello de que todo lo personal es político, porque no deseo que todo lo político me atraviese. $Y$ es precisamente contra ese modelo de sujeto $\mathrm{y} / \mathrm{o}$ de identidad subjetiva que se pretende instituir contra el que mi sensibilidad se revela.

Como mujer colombiana que trata de sobrevivir en un contexto de violencia, desearía que un país con tantos recursos tuviera la posibilidad de autodeterminarse para poder construir un espacio social donde la vida sea posible, donde los valores de la muerte y de la violencia llegaran a su fin, pero descubro que esto no es posible porque nuestros intereses no son los intereses de otros que bajo cierto tipo de mandatos "legítimos" parecen determinar desde hace ya no sé cuánto tiempo lo que debemos hacer y cómo debemos hacerlo. Por poner un ejemplo, no es posible que determinemos hacia dónde orientar nuestros recursos tanto materiales como de otra índole, porque existen "acuerdos" internacionales que median y priman sobre nuestras necesidades inmediatas y con los cuales nos hemos comprometido.

Para decirlo en términos existenciales, parece que la vida no tiene un ethos propio que la autorregule, sino que por principio la vida tiende hacia la destrucción y, por lo tanto, se hace necesario regularla, de tal forma que evitemos lo que parece ser un desastre inminente. Sin embargo, no creo que esta sea la experiencia de ningún ser vivo, pues lo que caracteriza la vida es su capacidad de autorregulación para mantenerse.
Lo que quiero plantear de fondo es que la discusión por el reconocimiento no es meramente una discusión por el reconocimiento en términos de las diferencias culturales, sino que las diferencias culturales ya están atravesadas por sistemas de organización a partir de los cuales se pone en juego su propia supervivencia, y que si entendemos los sistemas de organización a partir de los cuales los grupos se autorregulan, descubriremos que no podemos plantear la discusión en términos de reconocimiento o redistribución, porque esto introduce una distinción artificiosa y tendenciosa.

En efecto, el tema de la redistribución parece asociarse con cierta concepción de concentración de la riqueza que debe ser puesta en juego para que todos podamos acceder a ella de la misma forma y en las mismas condiciones. Frente a ello postulo que la riqueza es entendida aquí de forma unívoca y tendenciosa, pues en el país que me encuentro lo que veo es una gran riqueza en términos de biodiversidad, que me invita a pensar que no carecemos de los más mínimos recursos para procurar nuestra supervivencia y que por lo tanto no requeriríamos ser mirados en términos de sujetos que necesitan ser asistidos desde la riqueza de los otros. Lo que necesitamos es respeto por nuestra libre autodeterminación en términos políticos y culturales, que nos permitan echar mano de nuestras recursos para procurarnos nuestra propia supervivencia dentro de un modelo sostenible que respete las diferencias culturales de otros pueblos y que nos permita ser diferentes.

Ante todo esto me pregunto qué quiere decir aquello de la redistribución. Cuál es la riqueza de la cual somos carentes y por la cual se hace necesario demandar la redistribución antes que el reconocimiento. Tal vez la pregunta que haya que hacer es qué se esconde detrás de esta distinción, es decir, qué tipo de lógica, qué tipo de pensamiento, que tipo de episteme.

Para finalizar, quiero decir que la discusión entre Nancy Frayse y Judith Butler me parece muy interesante y solo quiero recordar que aquí únicamente estaba haciendo uso del derecho para soñar que el texto de Geyla Rubin me inspiró. 